\title{
A Circle of Learning: The impact of a narrative multilingualism approach on in-service teachers' literacy pedagogies
}

\author{
BELINDA MENDELOWITZ Languages Division, Wits School of Education \\ HARRIET DAVIS Languages Division, Wits School of Education
}

\begin{abstract}
This paper explores the impact of a narrative multilingualism approach on in-service primary school teachers who attended the Advanced Certificate of Education (ACE) Languages course at the University of the Witwatersrand in 2009. The teachers wrote their own language narratives and were required to implement language narrative work in their classrooms. The paper is a case study of three teachers' implementation of multilingual narrative pedagogy, and explores the ways in which each teacher translates this pedagogy into their specific contexts. Theoretically, the paper attempts to deepen and extend narrative multilingualism as an approach to language teaching. The notions of uptake and pedagogical translation are explored at various levels, namely, the teachers' uptake of a multilingual narrative approach and the learners' uptake. The most striking aspect of the data, across all teachers, is the process and dynamics unleashed in the classroom space. The process of sharing language narratives reconfigured dynamics in the classroom and opened up the classroom space for teachers and learners. The interventions that the pedagogy of narrative multilingualism afforded enabled the validation of linguistic diversity. In a society where xenophobia and linguicism is prevalent, such interventions can play a valuable role in changing attitudes and teaching learners to value difference. Furthermore, previously silenced learners found their voices and participated more in class activities.
\end{abstract}

\section{Introduction}

This article builds on previous research which argues that narrative multilingualism is a powerful means of creating awareness of linguistic diversity and identity issues among first year pre-service teachers (Mendelowitz and 
Ferreira, 2007; Ferreira and Mendelowitz, 2009). ${ }^{1}$ In this article, we explore the impact of a narrative multilingualism approach on in-service teachers' literacy pedagogies across subject areas with a specific focus on teachers' and learners' shifting attitudes towards multilingualism.

By narrative multilingualism, we mean a pedagogy in which reading and writing narratives about language histories and practices are central to the learning process. In particular, this pedagogy creates a space for the sharing of language histories and language practices among learners and teachers through narrative writing and storytelling, as well as critical reflection about self and other. We argue that it is highly productive to use the experiences of students as a starting point for exploring multilingualism.

The paper is a case study of three teachers' implementation and translation, in their own teaching, of the multilingual narrative pedagogy that they experienced on their Advanced Certificate in Education (ACE) course into their specific classroom contexts. We use the term translation of pedagogy to signify that this is a creative process. In the same way that stories are transformed as we retell them, and meanings shift when we translate from one language to another, pedagogy is reworked when a teacher transfers it from one pedagogic space to another, to meet the needs of a particular group of learners. Some translations may be more productive than others and there are times when the pedagogy may become 'lost in translation'.

This paper thus aims to answer the following overarching question: What is the impact of a narrative multilingualism approach on in-service teachers' literacy pedagogies?

The three central questions of this research are as follows:

1. How did teachers translate the narrative multilingualism pedagogy used in the ACE course and implement it in their classrooms? To what extent did they replicate or creatively rework the pedagogy in their classroom implementations?

2. How did language narrative work impact on classroom space and dynamics between teachers and learners and amongst learners?

3. What are the implications of the teachers' translations of this pedagogy for multilingual education?

\footnotetext{
${ }^{1}$ The ACE course material was adapted by Davis from an English One course for B Ed pre-service teachers at Wits University called "Language and identity"(Mendelowitz and Ferreira, 2007; Ferreira and Mendelowitz, 2009).
} 
In the article that follows, we will answer these three key questions through unpacking our theoretical framework, and then applying those concepts to the analysis of our dataset.

\section{Context and curriculum}

The research is located in Gauteng, which is a highly diverse linguistic area. This diversity is in turn framed by a society in which English occupies a hegemonic position despite there being eleven official languages and in which xenophobic attitudes are prevalent (with language being one of the key markers of identification and otherness).

More specifically, this research is located at the Wits School of Education and the students participating in the study are in-service primary school teachers who attended the ACE "Language in my World" course in 2009. This course is part of a semester long module called Languages A. This module is designed to meet the needs of both Foundation and Intermediate educators. It aims to provide both cohorts with expertise in teaching language and literacy in multilingual, multicultural classrooms; and to enhance their understanding of the role of language in the subject classroom. However, this paper focuses specifically on the Intermediate phase educators.

The students in this course are markedly different from undergraduate students, as they are generally of mature age and received teacher training prior to 1994. All the teachers are multilingual, with English as a second or third language. They teach in a range of urban schools, including Ex-Model C schools, township schools, inner city schools, and informal settlement schools. Their learners make up a multilingual and heterogeneous group, reflecting the social diversity that is characteristic of Gauteng communities. Frequently, the language of learning and teaching (LOLT) does not match the learners' home languages. This applies to both English as LOLT and African languages as subject and LOLT.

The focus of this paper is on the assessment task set for the "Language in my World" course (see Appendix A: Assignment 1 brief, Section B). The students were asked to write their own language narratives (Assignment 1, section A) and then in order to turn the gaze from their own world to that of the classroom, they were required to enact a similar narrative pedagogy in their own classrooms (Assignment 1, section B). The data from section B is the object of our analysis. 
Students were prepared for this assignment in a number of ways. By working through various exercises the students explored their own multiple social identities as well as their own use of different languages in different situations. Thereafter, they read examples of language narratives from a variety of contexts: South Africa, Australia and the USA. These served as models of narrative writing as well as points of comparisions with their own language histories. In addition, the instructors on the course modelled the practice of narrative pedagogy by sharing their own personal language histories with the students.

\section{Theoretical framework}

Theoretically, the paper attempts to deepen and extend narrative multilingualism as an approach to teaching about linguistic diversity (in the English as subject classroom and across other subject areas), and draws on the teacher learning literature to account for various levels of teacher uptake and translation. This is done in the context of a broader discussion about multilingual education.

\section{Narrative multilingualism: A narrative approach to multilingual education}

As multilingual education takes many different forms, it is necessary at the outset to define the version of multilingual language education that we are using. We are not working with the version in which different languages are used as the language of learning; rather we are working with the affective dimension, promoting respect for different languages through the use of a narrative pedagogy. This works at three levels: the learner re-valuing his/her language, the learners valuing one other's languages and the teacher re-valuing the learners' languages. We call this approach narrative multilingualism, and it includes working with affect and critical reflection in relation to one's own language and the language of others. In a similar vein, Phillion (2002) coined the term 'narrative multiculturalism' while conducting research on teaching and learning in a multicultural classroom in Toronto. She concluded that the multiculturalism literature/ theory were less useful than she had expected and at times tended to "obscure rather than shed light on the details of multicultural life" (Phillion, 2002: 275). This realisation led her to rethink multiculturalism as:

\footnotetext{
A fusion of narrative thinking and multicultural thinking ... a person - centred, experiential, relational way of thinking about researching and writing about the everyday experience of multiculturalism (Phillion, 2002: 277).
} 
In the same way, we argue that students can access the richness of linguistic diversity narratively, through exploring their own narratives, those of fellow students and a diverse range of published narratives.

There is a growing move towards the use of narrative in multilingual and multicultural education (Clark and Medina 2000, Phillion 2002, Busch, Jardine and Tjoutuka 2006, Mendelowitz and Ferreira 2007, Ferreira and Mendelowitz 2009) and more broadly as a powerful tool for teacher language education (Carter 1993, Ball 2003, Mendelowitz 2005). This move towards narrative is congruent with the view that multilingual practices are situated rather than abstract competencies. Blommaert, Collins and Slembrouck (2005) redefine communicative/linguistic competence as a negotiation of linguistic resources that is deployed differently across different contexts. An important aspect of this approach is an exploration of the relationships between languages and identity construction (Gal, 2006).Within this new paradigm of multilingualism, spaces have been opened for using personal narratives of language learning and language practices as tools for teaching and learning about linguistic diversity.

Clark and Medina (2000) use literacy narratives to facilitate pre-service teachers' understanding of literacy, pedagogy and multiculturalism in a predominantly homogenous context. They concluded that reading and writing literacy narratives enabled students to develop critical consciousness of literacy and diversity and to challenge and disrupt stereotypes about others (Clark and Medina, 2000, 73). In contrast to Clark and Medina, Mendelowitz and Ferreira (2007) have utilised a narrative approach for teaching highly diverse cohorts of pre-service teachers about multilingualism in South Africa. They conclude that language narratives (student and published) are a powerful educational tool, generating the opportunity for students to engage with multiple voices and to (re-) position themselves in a multiplicity of perspectives and experiences.

While the theoretical framework so far, has discussed narrative in the context of multilingual education, it is necessary to provide an overview of narrative as a way of knowing, and the features that we consider essential for both the conceptualisation of narrative multilingualism, and for the analysis of the data. It is to this section that we now turn our attention.

\section{Narrative ways of knowing}

Narrative as a 'way of knowing' has a number of distinctive features that are valuable for promoting teachers and learners' engagement with linguistic diversity. As a 'way of knowing' it is provisional and tentative, creating space 
for the expression of individual and personal experiences located in specific times, places, spaces and communities. It thus facilitates the telling and retelling of human experience in both individual and social contexts. We consider the ideas that follow to be applicable to both narrative writing and storytelling.

Narrative is a primary act of mind, a fundamental human capacity for making sense of the world we inhabit. This capacity for ordering experiences into stories is universal, cutting across all cultures and historical periods. A fundamental aspect of telling stories is the emotional component in relation to time, space and action. Kearney (2002) argues that narratives have a double role and provide the reader with a newly imagined way of being in the world. Kearney also examines the implications of narrative imagination for national identities. He claims that a nation can resist insularity by drawing on its own narrative resources to imagine itself otherwise, through its own eyes and those of others. We are interested in the ways in which teachers are able to re-imagine their classrooms through narrative multilingual work. We will apply these key concepts to the analysis of the data.

\section{Pedagogy}

The theoretical strands discussed so far relate directly to narrative theory and multilingual education research. However, these strands cannot account entirely for the different ways in which teachers translated their learning on the ACE course into their individual classroom pedagogies. To fully understand these moves, we need a theory of teacher uptake, and translation in relation to the narrative multilingual approach.

\section{Intake, uptake and reflection}

In the teacher education literature this process of teacher learning and transfer is frequently referred to as intake and uptake (Pennington, 1996). While intake refers to the process whereby accessible input is processed and internalised, it does not necessarily result in the application of those ideas to an individual's teaching context. Uptake, on the other hand, refers to internalised learning and the transfer of those ideas to an individual's teaching context. Pennington argues that reflection plays an important role in enabling teachers to process the input at deeper levels so that it ultimately becomes part of the teacher's worldview and classroom behaviour. A related issue is mastery of content knowledge as a prerequisite for productive uptake. It has been widely acknowledged in recent discussions about the literacy crisis in South Africa, that teachers frequently lack substantial content knowledge and that this serves as a barrier to productive pedagogical practices (Van Staden and Howie, 2010). 


\section{Methodology}

This research is a case study of three teachers' translations of the narrative multilingual pedagogy from the ACE course into their own classroom contexts. Each item of data consists of the teacher's description of their lesson, their reflection on the lesson and examples of learners' stories generated by the narrative approach. The full assignment included the teachers' own language histories, and we have drawn on these where relevant. We have also drawn on their second assignment, where relevant, to contextualise their teaching contexts. ${ }^{2}$ We have used thematic content analysis, as well as elements of discourse analysis, to analyse the data.

The three teachers' assignments were selected through a process of purposeful sampling. ${ }^{3}$ The full cohort consisted of one hundred and seventy students. Davis selected thirty from the larger dataset. We then did a preliminary analysis of the thirty assignments, and selected the three that illustrated emerging themes and pedagogies that were representative of key trends in the full dataset. A detailed profile of each teacher is provided per case study. It should be noted that we made a decision not to edit the extracts from students' assignments.

The description and analysis that follows engages with the first two research questions concerning teachers' translation of the narrative multilingualism pedagogy into their classrooms and its impact on reconfiguring the classroom space and dynamics.

\section{Description and analysis of data}

Case study 1 - "Opening gates and walking tall": inclusivity, cultural pride and accommodation.

Mashudu teaches Grades Six and Seven at an ex-Model C school in the suburbs. Thirty seven percent of his learners are foreigners. His first language is Tshivenda.

Mashudu's description of his pedagogy was extensive. He used the ideas from the ACE course as a springboard and then transformed them creatively. While the ACE course exposed learners to language narratives from a variety of contexts, Mashudu chose to use cultural practices associated with different linguistic groups as an entry point into sharing language narratives. Instead

${ }^{2}$ In the second assignment teachers investigated teaching and learning at their schools as well as their schools' language policies.

${ }^{3}$ The names of the three teachers have been changed. We obtained written permission from the three teachers to use their work for research purposes. 
of beginning the lesson with the telling of his own language narrative (as most teachers did), he began with a video of African dance set in Botswana. Hence, he provided learners with a different kind of model and modality, but one which was suited to his purpose. He described the opening of his lesson as follows:

I played a video of an African dance and then after the video I asked the class to sit in their ethnic groups. I then asked them to come up with a song or poem or a story from their own language. Each group was then given a chance to show-case their work and interpret to the whole class their work. If it was a song they had to tell us what it is about. I chose this method because it makes everyone important and when they show case their work they feel important. The video was my choice based on the fact that it was a wonderful piece of work which the Botswana had done and everybody loves it and was proud of them. So I wanted to rub that pride to them and start to walk tall about their languages.

Mashudu's sense of ownership and agency of his pedagogy is reinforced through his use of the phrase "my choice". Pedagogy at its most productive is about teachers exercising choices and how to implement ideas and mediate learning. Mashudu provides convincing reasons for his choices.

There are two different discourses operating in this opening description: a cultural tourism discourse and cultural pride. How do these two discourses work together and what tensions arise between these two discourses? Mashudu's overarching aim is clearly to promote sharing, recognition, and celebration of learners' diverse languages and related cultures. In order to do this he divides them into ethnic groups and invites them to "show case" an aspect of their language and culture. In his repeated use of "show case", the discourse of cultural display for outsiders is reinforced. This is reminiscent of Ipi Tombi in the seventies and other similar performances where African culture is put on display for outsiders. In addition, Mashudu's organisation of the class into ethnic groups, although well intentioned, assumes that there is a linear uncomplicated relationship between language, identity and culture in a heteroglossic society.

Running alongside the 'cultural tourism' discourse, the discourse of inclusivity is strongly developed. His choice of the Botswana dance video is designed to appeal to all the learners, as "everybody loves it". He may have intentionally not chosen a South African ethnic group, given the large number of foreigners in the class. Certainly the aim of his method was to "make everyone feel

${ }^{4}$ Ipi Tombi was a musical staged in South Africa in the seventies that showcased African culture. Ironically, it was performed in segregated venues for a white audience. 
important". Metaphors of cultural and linguistic pride abound such as "rub that pride in" and "start to walk tall", and these reinforce his stated aim. Both the metaphors suggest that learners' home languages are frequently marginalised at school, and that this lesson is a starting point for bringing about change.

The learners were "fascinated" by the video and Mashudu used this response as a starting point for discussions about learners' feelings about their cultures and their understanding of culture as a concept. He explained:

This process then opened a gate for me to introduce the language. I then showed them that language is power and is one of the most important instruments we use to be heard and understood.

The metaphor of 'opening a gate' recurs in his response and refers here to opening up classroom space for sharing language and culture, and later he uses it to refer to the ACE course as empowering him to open his mind to new possibilities: "I feel so empowered by Wits to help me open up such a gate". Once the gate was open, learners worked in their groups to prepare a song, poem or story in their own language, which they then presented and translated.

Mashudu's work raised really interesting questions about how to deal with difference productively, while the route he chooses runs the risk of perpetuating cultural and ethnic stereotypes. However, his detailed reflection on the impact of his lesson suggests that this was not the case.

Mashudu focuses on both the short term and long term impact of his language narrative work, suggesting that the learning continued long after the lesson and that the impact of the lesson exceeded his expectations: "Little did I think it will take such a step."

He commented:

If I were given a chance to reintroduce this lesson I will still go the same way because it makes learners to open up and feel free to do the exercise. What I have learned is that when we used English only as language the learners feel that their languages are not important. Through this lesson, learners were proud of who they are and I felt good that I have done something about it.

In this reflection, Mashudu points towards the way the narrative pedagogy reconfigures the classroom space and frees the learners from the usual constraints, in terms of language, identity and self-expression. The lesson facilitated the reversal of the usual language hierarchy, and made marginalised 
languages and related cultural practices visible. Mashudu considers this shift both in terms of local languages and the languages of foreign students. He is particularly struck by its impact on foreign students, who have been rendered invisible, struggling silently, until this point:

The Congolese have started to share their culture with us with pride. ... It has also helped the parents to come to school and offer to teach the learners their different dances of their ethnic group.

Mashudu also comments that the lesson gave students who do not usually participate an opportunity to do so. This enabled him as teacher to get to know his learners at a different level. He illustrates this point by providing vignettes/ retelling the stories of two students of marginalised languages. In his retelling of the quiet struggles of these learners, he expresses admiration for their courage and determination to overcome difficult circumstances. The manner in which he retells these stories speaks volumes, is free of any deficit/ victim discourses and is framed by acknowledgement for their achievements. He comments: "I have seen an enthusiasm that I dearly need to see on day to day. I also notice that other kids envy those who understand other languages."

Thus, the learners began to see multilingualism as a valuable resource. As a follow-up to this lesson, the learners introduced a daily practice of greeting and saying prayers in different languages. He also notes a long term shift in classroom dynamics that extends into other learning area.

Other learners are now opening themselves to learn. I notice this when I interact with them during Life Orientation. They express how they are learning and what it feels like.

This is a powerful conclusion that highlights the relationship between narrative, affect, learning and re-imagining in a specific time and space. Another striking aspect of this case study is the growing sense of agency and empowerment experienced by Mashudu and his learners. It seems that the lesson not only freed the learners, but freed Mashudu as a teacher. These themes are picked up and developed in different ways in the other two case studies. 
Case study 2 - Widening the circle of learning: transformation, social
justice and diversity

Sello teaches Grade Six and Seven at a small community school situated near the inner city. His home languages are Zulu and Siswati.

Sello is very innovative and has a transformation agenda which is evident in his response to Assignment Two where he had to do some research into language learning and teaching in his own school. He makes the following point about change:

I mean this is a new era and things need to be done in line with today's order especially in the education sector, we need a shift in mindset.

He takes ownership of the narrative multilingualism pedagogy, finding his own ways to use it as a tool for the exploration of his students' language repertoires. Working in a distinctive way is important to him. In describing teaching at his school he remarks that "pedagogy and teaching styles vary from one individual to another. As individuals we are but uniquely us and that's a vital element that we all employ in our daily practices."

In the light of his commitment to shift his practice it is interesting to look at his translation of the ACE narrative pedagogy in his classroom. He creatively reworked the ACE language narrative activities by extending the scope, depth and levels of learner participation. Sello reflected on his reasons for presenting this topic in four different activities:

My reason for this was to ensure that all learners with different abilities are catered for especially those who still struggled to write or describe in writing.

In order to promote inclusivity, Sello began the lesson by asking learners to introduce themselves and list which languages they speak in different domains. He reflects that this gave his learners an opportunity to learn about one another's language backgrounds. This knowledge is often hidden because the children come from a variety of language backgrounds. He explains that many of his learners are "asylum seekers mainly from West Africa and lately from Zimbabwe". Consequently, learners code-switch to accommodate one another, or else they tend to operate in the main languages of the school as "the Nguni dialects especially isiZulu and isiXhosa are leading the pack". 
In the second activity he required the learners to create a visual representation of their shifting language usage in different domains and the related role changes such as learners, sons, daughters and peers. In this instance he replicated the basic activity from the ACE course. However, he extended it by asking each language group to choose one learner to present his/her languages diagram orally to the whole class.

In the third activity Sello extended the circle of learning to include contributions by parents and caregivers. He designed an assignment in which the learners were required to ask their parents/guardians to tell a traditional story in their mother tongue language. Hence, the individual child became a researcher and meaning maker. On returning to class the learners had to retell the story. They were instructed to pay attention to the "use of gestures so their audience/class can follow". Thus, storytelling is seen in terms of display of knowledge and performance. The learners were encouraged to make use of a number of ways to tell and share the story. This phase of the lesson further increased the opportunities for learner participation as they had to "prepare two /three questions about the story i.e. the moral of the story or something about the characters". In so doing, his learners were able to engage with other features associated with narrative work such as retelling, performance and active listening. Furthermore, the posing of questions placed the learners into a situation where they could provide input and negotiate meaning. This move has implications with regard to power relations because the teacher now becomes a facilitator as opposed to the more conventional transmitter of knowledge, and it creates spaces for the teacher and his learners to become co-constructors of knowledge.

These initial oral introductory discussions helped the learners to share and gain confidence with their material before moving on to the difficulties associated with the final (fourth) independent written reflective activity. This is an important issue in all languages classes but particularly in the multilingual classroom where additional language learners frequently find writing more difficult than the oral mode.

In this final activity Sello instructed the learners to write their own language stories:

I asked them to use their own individual languages diary to write about their daily language experiences. I gave them some questions as guidelines...they had to describe not answering the questions but using them as guidelines. 
Sello has now transformed the ACE version of this task, so that these stories are not histories or accounts of past experiences, but concentrate on the learners' current language practices across domains.

Having discussed the various phases of his lessons, it becomes clear that he has created opportunities for learners to work with a range of meaning-making modes (i.e. oral, written, visual and performance modes) and resources and audiences (i.e. self, peers and, in the third and fourth activities, in a wider context with family).

In the reflection section of his assignment Sello makes some very interesting comments on multilingualism. In this regard the task helped him to learn that children from Soweto and Alexander townships had "more diverse experiences than those living in and around the suburbs". By this he is referring to the multilingual nature of Gauteng townships, including the use of hybrid urban varieties. He realises that multilingualism is complex and multifaceted. While it facilitates accommodation and communication, he expresses concern about language loss. He noted that "as they told their stories I realized that most of them were struggling to express themselves in their own languages and they would every now and then code switch to English". The limited ability to communicate in their languages of their parents caused him to say that "as much as multilingualism has many advantages it also carries with a fair share of disadvantages." This issue is developed by Nomsa, the third teacher in the study.

Nevertheless, the narrative afforded Sello a rich dynamic space in his multilingual classroom for recognizing and valuing individual language use, and the need to avoid discrimination on the basis of language. He expresses the hope that for his learners the task "demonstrated that all languages are important and there's no language which is superior or inferior to others."

\section{Case Study 3 - "From their stories I learned a lot": multilingual matters, mismatches and linguicism}

Nomsa teaches Grade Six in a school in the township of Katlehong. Her home language is Zulu.

While Mashudu and Sello provided rich details about their lessons and reflections, Nomsa's description of her pedagogy was somewhat thinner as was her reflection on her pedagogy. However, she reflected extensively on what she learned about multilingualism from the learners' assignments and included interesting examples of learners' language histories to illustrate these issues. 
Initially, Nomsa worked tentatively and somewhat unimaginatively as she did not transform and redesign the introduction to the task. The following account shows that she began via a conventional, transmission mode:

I told learners to list the official languages. After mentioning all of them I asked them to mention languages they know or speak at school and at home.

She does not provide details about the learners' responses to these questions nor does she provide details about how the task was mediated and whether it was organised in pairs or groups. However, she enthusiastically elaborates on her subsequent sharing of her language history with the learners and her hope that this process of sharing and modelling will inspire the learners to tell their stories. She explains:

I told them my language history, where I came from, languages that I acquire when I grew up i.e. at school, neighbours, high school, tertiary and at work. I did this because I wanted them to be free when they told their language histories.

Nomsa recognises the power of modelling the storytelling practice and in so doing she hopes that the dynamic of the class will become more vibrant as she explains that she "wanted them to be free when they told me their language histories." There appears to be a tension between her desire to create a narrative space in the classroom and her use of transmission discourses at the outset of the lesson, which positions the learners as passive subjects who are required to follow the teacher's instructions, answer questions and list information. Perhaps related to this ambivalent pedagogy, there is a suggestion that she did not satisfactorily achieve her desired outcome of making the learners "free", as she says that the learners were "shy to talk in front of their classmates".

As a follow-up task to the oral telling of the learners' language histories she gave them homework to write about their language histories. Here she had more success as "others did very well they understood the topic even the shy ones managed to write... and I think I will do it again in future". Like Sello she has seized the opportunity to widen the learning circle by including the parents as her learners were told to write their stories at home "with the aid of their parents".

In 2008, South Africa experienced a series of violent attacks on foreigners. One of the features of these incidents was the use of language as a marker of the "other". Through this narrative lesson she learned about the link between language use and identity and the impact of linguicism (language prejudice) 
in the wider social community on her learners. She comments: "From their stories I've learnt a lot. Others lost their fathers because of xenophobic attacks. This made them not even to concentrate in class."

She also shows that she also came to learn about linguicism in the narrower social world of the family. She elaborated on this issue:

I realised that learners experience difficulties in situations whereby a learner have parents who speak different languages i.e. mother is speaking Zulu where else father is speaking Shangaan, Sotho, Pedi or Xhosa etc. One parent want to dominate at home like children have to speak his her language at the expense of the other one, and no one seems to compromise that put a child in a tight corner.

She explores the result of this requirement that within the family, children need to speak to each parent in his or her language. She feels this creates confusion and she notes that learners "expressed heavily their feelings and disappointments. That taught me a lesson as a mother to avoid putting kids in that embarrassing situation". What is striking is her affective engagement with these issues, and her empathy for the challenges facing learners in multilingual landscapes.

Like Sello, she seems to be concerned about the issue of power relations associated with language use as in her own language narrative she foregrounds some difficulties experienced beyond the context of school. For her, living in a multilingual society leads to confusion and a feeling of being alienated, inhibited and frustrated at the lack of accommodation from the speakers of other languages.

My worst experience was in Venda. I couldn't communicate with them to socialize. I wished heaven could open and swallowed me. They didn't compromise, they spoke Venda all the time.

The notion of 'compromise' and 'accommodation' are clearly important to her as a way to facilitate productive communication in a multilingual society. She observes that her learners seem more able to 'adjust themselves' than their parents as "when playing with friends they speak other languages, that means they have to codeswitch in order to belong or accommodated in that specific group....at school they meet different groups speaking different languages." This contrasts with her own experience of alienation and exclusion that she experienced in Venda. 
In terms of pedagogy, Nomsa's learning on the ACE course seems to be at the intake phase, rather than the uptake phase. She has clearly internalised the course input, but has not reshaped it substantially for her classroom context. However, there is evidence of a significant affective shift in her attitude towards the learners, based on what she has learned from their assignments. This is likely to ultimately reconfigure her relationships with learners. Her conclusion points in this direction:

And I promised to help those that are traumatised due to xenophobia, and seek help for them in order to make them accommodated at schools and in the environment where they live.

\section{Discussion of findings: comparisions across teachers}

It seems fitting to liken the process of pedagogical translation to Eva Hoffman's (1989) account of learning to speak a new language as an immigrant in her seminal autobiography Lost in Translation:

Since I lack a voice of my own, the voices of other invade me as if I were a silent ventriloquist. ...I do not possess them yet; they possess me. ...Eventually the voices enter me; by assuming them I gradually make them my mine. I am being remade, fragment by fragment, like a patchwork quilt; there are more colours in the world then I ever knew (Hoffman, 1989: 220).

Hoffman raises issues about taking on something unfamiliar and the process of making it your own. The initial phase may include replication, ambivalence, using this new resource with limited understanding; and a loss of control. The second phase includes a shift towards ownership, and agency as well as new possibilities, access to new experiences and new ways of seeing. The teachers engaged in a similar process and remade their pedagogy in different ways, to different degrees of re-invention. Having provided a detailed case study of each teacher we now attempt to compare these processes of pedagogical translation and to account for the differences that surfaced.

Mashudu and Sello clearly exemplify what is possible when teachers have a good grasp of content knowledge and language proficiency in the LOLT (We refer here to the LOLT of the ACE course, English). However, while this is a necessary base for productive uptake, it does not guarantee a transformed and imaginative pedagogy. Both went way beyond the ideas provided in the ACE course in terms of activities, modalities and scope. So what was at play here? 
What is salient to both teachers is that they took ownership of the pedagogy, and exhibited agency in their pedagogical translations. Mashudu and Sello set their own imaginations free from the usual institutional constraints, and in so doing were able to create a more flexible space for their learners. Sello values the individual and personal element of pedagogy and believes that it is important for each teacher to have the space to develop their own unique style. Similarly, Mashudu views himself as exercising pedagogical choices.

In terms of content knowledge, both teachers embrace the new ideas that they have been exposed to from the ACE course and the subsequent lessons with their learners. This is powerfully manifest when they report with conviction and pride on the reconfigured dynamics in their classrooms: the opening of a narrative space, increased participation and collaboration between teacher and learners, the validation of diversity and the sudden visibility of previously marginalised languages, and the new knowledge of learners' linguistic histories and identities.

Nomsa provides an interesting contrast to Mashudu and Sello on a number of levels. She grasps fragments of the new pedagogy but is still uncertain and ambivalent. She replicated the pedagogy from the ACE course at a fairly basic level and was unable to own and transform it. While she was disappointed with the limited responses from learners, her use of transmission and instructional discourses raises questions about her willingness to deviate from the teachers as sole authority script.

However, despite these limitations, there were small shifts in her classroom and her determination to repeat the lesson next year indicates that an idea has taken root. Unfortunately, her reflection provides no indication of how she will change her pedagogy to generate more learner participation and engagement. This resonates with Pennington's point (1996) about the relationship between deep reflection and teacher uptake, and conversely, limited reflection and intake.

\section{Conclusion}

This article has shown that using a multilingual narrative approach to multilingual education has a potentially powerful impact on teachers, learners and in some instances, parents. We write this article in the hope that other teachers and language teacher educators will be inspired to continue the circle of learning in their own contexts, whether they might be in urban townships, in leafy suburbs or under a tree in a forgotten corner of the country. It is a rich and 
rewarding journey and one that can never be completed, given the dynamic nature of languages in South Africa and the rapid rate of change.

It has been a layered journey, starting with the language narrative work with pre-service teachers (Mendelowitz and Ferreira, 2007). Each new cohort contributes something new to our evolving understanding of language attitudes, practices and experiences in South Africa. We are as much teachers as learners in this process of developing and refining a narrative multilingual approach to multilingual education.

The ACE cohort, which is this focus of this article, has contributed to our understanding of the constraints and benefits of translating this pedagogy into South African urban classrooms. The article focuses on three teachers who are representative of key trends in the broader dataset. Using a narrative multilingualism pedagogy on the ACE course generated awareness of linguistic diversity which teachers translated into their own classrooms, in different ways and to different levels of innovation and transformation. The case studies of Mashudu and Sello highlight what it is possible to achieve when teaching linguistic diversity using a narrative multilingualism approach. Nomsa's case study, while tentative in terms of pedagogical change, shows that powerful learning occurred which changed the way she viewed her learners. This is an important step in beginning to create a narrative space in the classroom.

\section{References}

Ball, A. 2003. US and South African teachers' developing perspectives on language and literacy: changing domestic and international roles of linguistic gatekeeping. In Black linguistics: Language, society and politics in Africa and the Americas, S. Makoni, G. Smitherman, A.F. Ball, A.K. Spears (eds). London: Routledge, 186-215.

Blommaert, J., Collins, J. and Slembrouck, S. 2005. Spaces of Multilingualism. Language and Communication, 25: 197-216.

Bruner, J. 1986. Actual Minds, Possible Worlds. Cambridge: Harvard University Press.

Busch, B. 2006. Language biographies - approaches to multilingualism and education and linguistic research. In Language biographies for multilingual learning, B. Busch, A. Jardine and A. Tjoutuku. Cape Town: PRAESA/ UCT.

Carter, K. 1993. The Place of Story in the Study of teaching and Teacher Education. Educational researcher, 22(1): 5-18.

Clandinin, J. and Connelly, FM. 2000. Narrative Inquiry: Experience and Story in Qualitative Research. San Francisco: Jossey-Bass.

Clark, C. and Medina, C. 2000. How Reading and Writing literacy Narratives Affect Preservice Teachers' Understandings of Literacy, Pedagogy, and Multiculturalism. Journal of Teacher Education, January-February, 51(1): 63-76.

Delpit, L. 1995. Other People's Children: Cultural Conflict in the Classroom. New York: The New Press. 
Danielewicz, J. 2001. Teaching Selves: Identity, Pedagogy, and teacher Education. New York: State University of New York Press.

Ferreira, A. and Mendelowitz, B. 2009. Opening up the contact zone: an undergraduate English course as multilingual pedagogic space. English Teaching: Practice and Critique, Special issue: Subject English in bilingual and multilingual settings: Embracing the linguistic other, 8(2): 54-79.

Gal, S. 2006. Migration, Minorities and Multilingualism: Language Ideologies in Europe. In Language Ideologies, Policies and Practices: Language and the Future of Europe, C. Mar-Molinero and P. Stevenson (eds). Basingstoke: Palgrave, 13-28.

Hoffman, E. 1989. Lost in Translation. London: Minerva

Kearney, R. 2002. On Stories. London: Routledge.

Mendelowitz, B. 2005. Representing shifting selves: Reflections on teaching memoir writing to pre-service teachers. Perspectives in Education, 23(1): 15-24.

Mendelowitz, B. and Ferreira, A. 2007. Engaging narratives: Using language biographies to facilitate learning. SALALS (Southern African Linguistics and Applied Language Studies), 25(4): 487-504.

Norton, B. 1977. Language Identity and the ownership of English. TESOL, 31(3): 409-429.

Phillion, J. 2002. Narrative multiculturalism. Journal of Curriculum Studies, 34(3): 265-279.

Pennington, M.C. 1996. When input becomes intake: Tracing the source of teachers' attitude change. In Teacher learning in language teaching, D. Freeman and J.C Richards (eds). Cambridge: Cambridge University Press.

Van Staden, S, and Howie, S. 2010. South African teacher profiles and emerging teacher factors: The picture painted by PIRLS 2006. Reading and Writing, 1(1) 47-60. 


\section{APPENDIX A}

\section{Part 1: Language in My World}

\section{Assignment 1}

Note that this assignment is made up of two sections: Section A and Section B.

\section{SECTION A: Writing Your Language History}

(50 marks)

Write a minimum of 3-4 pages if handwritten or 2 pages if you type. For typed essays please use 12 font and 1.5 spacing.

Now that you have read the language histories of Mathakga Botha, Gloria Anzaldua, Richard Rodrigues, and Trevor Chauke you will see that these writers had both positive and negative experiences.

Your task is to write your language history in which you describe both the positive and negative experiences you have had. Thereafter, you must reflect on the meaning of these experiences and then you must analyse these experiences by looking back at the metaphor on 'interrogation' and also by making links to (indicate similarities and differences) to the language histories that you have read.

When you describe, include information on any of the following that are relevant to your language history:

- Which language or varieties of one or more languages you understand/ speak/read and write;

- Which language or languages were spoken around you when you were a baby;

- In what language did you utter your first word;

- Who influenced your language development in what language or languages did you learn to read and write;

- What language(s) did you use during your childhood;

- Which learning experiences have been positive or negative and why you found them so; 
- The contexts in which you use different languages or language varieties that you know; the language variety that you find comfortable or difficult to use and why.

\section{SECTION B Learners' Language Histories}

(50 marks)

Now that you have read a number of language histories or narratives and even written your own you might want to see how you can make use of a similar exercise in your own classroom.

- If you are an Intermediate/Senior Phase educator ask your learners to write their language histories. Obviously for Intermediate/Senior Phase learners you would not expect as much detail and complexity that you put into your work.

- If you are a Foundation phase educator ask your learners to tell you and the others in the class the story of their language history

For this assessment complete the following tasks:

- Write a description (1 paragraph) of how you presented this topic to your class (5 marks)

- Reflect (1 page) and then indicate how you think the task worked. Comment on whether you would repeat it or adjust it in some way in the future.(10 marks)

- Include a few of your learners' language histories as examples of the work that you did. If you are working with foundation learners you might want to describe some of their stories. (5 marks)

- Comment (1-2 paragraphs) on your learners' responses. Discuss firstly what you as a teacher learned from the activity; and then discuss what you think the learners gained from the activity. (10 marks).

\section{Acknowledgement}

We wish to thank our colleagues Pinky Mokoe and Ana Ferreira for their valuable feedback on this article. Thanks also to our colleagues who taught on the ACE course and provided us with copies of their students' language narratives: Lesley Masterson and Joanna Parmenter.

We are grateful to the three teachers who gave us permission to use their assignments for this article. 
